\section{Skeggs, Leonard Tucker Jr.}

\author{
O. A. Gressner ${ }^{2}$ und A. M. Gressner ${ }^{1}$ \\ ${ }^{1}$ Labor Dr. Wisplinghoff Berlin, Berlin, Deutschland \\ ${ }^{2}$ Labor Dr. Wisplinghoff Köln, Köln, Deutschland
}

Lebensdaten Amerikanischer Mediziner, geboren am 09. Juni 1918 in Fremont, Ohio/USA, gestorben am 04. Dezember 2002 in Cleveland, Ohio/USA. Studium an der Youngstown State University, OH. Master's Degree (1941) und Doktorand (1948) in Biochemie an der Western Reserve University, Cleveland (WRU). Direktor des Hypertensionslabors am Cleveland Veterans Affairs Hospital. 1992 Gründung der Leonard und Jean Skeggs Stiftungsprofessur für Biochemie. Im Jahr 1997 Aufnahme in die Cleveland Medical Hall of Fame.

Verdienste Skeggs und sein Kollege Jack Leonards entwickelten im Jahr 1948 den als „künstliche Niere“ bezeichneten ersten Plattenhämodialysator. Ebenfalls wurde durch Skeggs der Grundstein für die Entwicklung der ACE-Hemmer im Jahr 1956 mit der bahnbrechenden Aufklärung der Funktion des ,angiotensin-converting enzyme“ (ACE; > Angiotensin- konvertierendes Enzym) gelegt, wofür er 1968 mit dem Vernon Stouffer Award ausgezeichnet wurde.

Skeggs ist jedoch v. a. für die erste Konzeption von einem teilautomatisierten $>$ Analysegerät für die Laboratoriumsdiagnostik Ende der 1940er-Jahre bekannt, durch dessen Schlauchsystem ein kontinuierlicher „Strom von Reagenzien“ geschickt wurde, die fotometrisch analysiert und über einen Rechner ausgewertet werden konnten. Dieses Verfahren wurde jedoch erst 1954 durch die New Yorker Firma Technicon Corp. weiter kommerzialisiert. Der hieraus hervorgegangene Prototyp des „Autoanalyzer Technicon“ konnte 12 Parameter des Blutserums bestimmen und war bis 1970 in zahlreichen Laboratorien in Gebrauch (s. Abbildung im Eintrag $\triangleright$ Analysegerät).

\section{Literatur}

Lewis L (1981) Leonard Tucker Skeggs-a multifaceted diamond. Clin Chem 27(10) 1465-1468

Skeggs LT (1957) An automatic method for colorimetric analysis. Amer J Cin Pathol 28:311-322 